\title{
A Survey of Benchmarking Practices in Higher Education in Kenya: The Case of Public Universities
}

\author{
Peterson Obara Magutu ${ }^{1}$, Isaac Meroka Mbeche ${ }^{1}$, \\ Stephen Onserio Nyamwange ${ }^{1}$ and Richard Bitange Nyaoga ${ }^{2}$ \\ ${ }^{1}$ Department of Management Science, School of Business, University of Nairobi, Nairobi - Kenya \\ ${ }^{2}$ Department of Management Science, Narok University College, Nairobi - Kenya
}

\begin{abstract}
Benchmarking has been used as a tool, a methodology and a technique for continuous improvements in sectoral operations to gain and maintain competitive advantage. This was a survey of benchmarking practices in higher education in Kenya, the case of public universities, whose objectives were; to document the benchmarking activities in the public universities; to establish the challenges facing the public universities in benchmarking. Cross sectional survey was used in this study to collect data from the six public universities with their respective campuses/schools in the population of interest. The respondents were senior administrators and the academic staff. Of the 53 informants who were sampled, 31 responded, thus, a response rate was of 58 percent.
\end{abstract}

Descriptive statistics were used to analyze and summarize the data before presenting it in the form of proportions, means, tables and graphs. This was in line with the first and second objectives, which were actually answered in relation to the benchmarking practices in the academic function of public universities in Kenya. The study found out that continuous improvement systems in Kenyan public universities are good, not excellent. The external drivers of change/continuous improvements in public universities are the customers/students as opposed to legislation, while the major internal trigger of change is the actual performance. The public universities effectively and successfully benchmark for continuous improvement. The Kenyan public universities use action research and performance indicators as the sources of referencing information on benchmarks. The most common type of benchmarking in use is development/improvement benchmarking and planning to make use of international benchmarking. Finally, the three critical factors that have influenced the success of benchmarking practices are: time and resource availability: limited duration, comparability and compatibility, which are reasons why the institutions don't practice international benchmarking.

Keywords: Benchmarking, Continuous Improvement, Quality, Higher Education

\section{Introduction}

\section{General Background}

Benchmarking has been used as a tool, a methodology and a technique for continuous improvements in sectoral operations to gain and maintain competitive advantage. Participating on benchmarking has promoted a culture of thinking about quality, assessing one's own performance and taking responsibility for it. This is aimed at improving customer relations and promoting self-criticism. Depending on how

Copyright (C) 2011 Peterson Obara Magutu, Isaac Meroka Mbeche, Stephen Onserio Nyamwange and Richard Bitange Nyaoga. This is an open access article distributed under the Creative Commons Attribution License unported 3.0, which permits unrestricted use, distribution, and reproduction in any medium, provided that original work is properly cited. Contact author: Peterson Obara Magutu e-maill: magutumop@uonbi.ac.ke 
excellent, good, bad or indifferent an organisation's operations are, it determines the direction, urgency and priorities for a sound base of appetite for change and for a continuous drive to enhance quality. At its simplest competitive performance standard, it would consist merely of judging whether the achieved performance of an operation is better than, the same or worse than that of its competitors (Norman, 2001).

The first international benchmarking was undertaken in mid-1990s (Wragg, 1998; Fielden \& Carr, 2000; Mackie, 2000). Jackson (2001) noted that the challenge for higher education will be to develop benchmarking in a way that will help people learn and improve their own practice while improving the overall capacity of the system to develop, improve and regulate itself. The term benchmarking was first used by Rank Xerox to describe a process of selfevaluation and improvement through the systematic and collaborative comparison of practice and performance with competitors in order to identify own strengths and weaknesses and learn how to adapt and improve as conditions change (Camp, 1989). Benchmarking has been quickly adopted by many sectors of business and industry as part of the quality movement (Spendolini, 1992). The education sector is no exemption. The first use of the term in an educational sense is accorded to Melton, "Standards represent benchmarks with which students compare their ability and performance" (Student Physician, 1957).

Benchmarking provides a clear signal of success or failure as it has been widely recognised as a technique that can dramatically improve process performance to best practices level. Leibfried and McNair (1992) studied benchmarking within continuous improvement and insisted that benchmarking is the most recent methodologies that have emerged in corporate attempt to gain and maintain competitive advantage. Conceptualisation of benchmarking at its simplest level can be viewed as a strategy for enabling people to think outside the boxes they normally inhibit: the boxes being departments, services or functional units of institutions (Spendolini, 1992).
All these arguments stress the fact that benchmarking as used to denote excellence or a mark of distinction in a product or service, is a versatile tool in the service sector, both in profit and non-profit making set ups. The changes in higher education are because of five primary factors: higher public expectations over what universities should be delivering; increasing parental concern about the quality of education; greater emphasis on college ratings; demographic changes in student population; and higher costs (Oketch, 2009). In the changing environment, producing more is not always better. Yet, most universities have increased student: staff ratios and costs. For them to compete in the global environment, universities must have quality beyond the competition, technology before the competition and costs below the competition (Watson, 1996).

Benchmarking is one of the methods higher education institutions can use to help them achieve the objective of efficiency and costeffectiveness in optimising the resources available to support learning. Benchmarking processes that are focused on standards of learning might be directed towards: the intended outcomes; what the learners will be expected to know and be able to do. These are processes that enable outcomes to be achieved. These are therefore, means by which the learners will be enabled to achieve: the expected outcomes, curriculum, teaching and learning methods and support and guidance systems; outcomes actually achieved. This will enable the learners demonstrate the achievement of specified educational outcomes and the actual standards achieved. This is the framework on which QAA (1998a) subject benchmarking is predicted (Jackson, 2001).

The essence of benchmarking is learning from others, understanding of whom and the benchmarking partners' performance level both for comparison and for registering improvement, comparison of performance levels, levels of processes and practices to meet the obligation of making improvements on continual basis and improving efficiency with respect to best practices (Dewhurst et al., 1999). 
Benchmarking, therefore, is a continual systematic measurement through comparison that frequently seeks fresh approaches, following implementation of improvements and reviewing the benefits (McNair and Leibfried, 1992).

Benchmarking has traversed four distinct generations: The first generation: - reverse engineering was characterised with initiatives of teardown and technical product analysis. The second generation: competitive benchmarking which involved comparisons of processes with those of competitors. This is where benchmarking was refined into science by Xerox, mainly during 1976-1986. Third generationprocess benchmarking: -where it was realised that learning can be made from companies outside the industry and required more in -depth knowledge and understanding. Fourth generation: strategic benchmarking which involves a systematic process for evaluating alternatives, implementing strategic and improving performance by understanding and adopting successful strategies from external partners (Watson, 1996).

The objective of benchmarking as one of the performance management strategies is setting realistic performance standards (Nahmia, 2000). It is also concerned with searching new ideas and practices, which must be able to be copied or adapted. The success of benchmarking, however, is largely due to more than its ability to set performance standards and enable organisations to copy one another. It is essentially about emulating, creativity and innovation (Cartin, 2000).

Laeven and Smit (2003) noted that the development of a benchmarking system is no mean understanding. They use a set of instruments in the Dutch libraries and they prove the value of benchmarking as a tool to achieve quality management rating very highly. A number of researches have been carried out in this area reflecting the range of approaches and application in business, administration and academic process.

A number of studies on benchmarking assessment practice were also reported in the UK Pilot studies in Benchmarking Assessment Practice (QAA, 1998c). In a study by Bridges et al. (1999), the frequency distribution characteristics of over 90,000 undergraduate module marks in eight subjects were pooled and examined. The analysis revealed systematic differences in marks distribution due to deep-rooted marking traditions that transcend institutional cultures or regulatory regimes and which ultimately give rise to the wellknown variations in degree classifications in each subject (HEQC, 1996). This and others raised questions about the differential demand on learners for different assessment methods and strategies used.

Lund (1998) and Town (2000) have studied how academic libraries in the UK utilised benchmarking in 20 institutions with respect to availability of up-to-date stock, staff development ability and approachability, user experience, education and feedback, innovation and learning environment. Their focus is on four key best practices and processes: user induction/education, information retrieval, information provision and delivery and facilities provision. This gave a first practical experience of benchmarking to a wide number of practitioners throughout the sector. Price (2000) notes a distinctive approach to the benchmark practice relating to the management of built and serviced environment based on a process of action research and active learning among those involved.

\section{Higher Education in Kenya}

Kenya has attached education to economic and social development since 1963 (Sifuna, 1998). This led to the rapid expansion of the education system to provide qualified persons for the growing economic and administrative institutions and to undertake some reforms to reflect the aspirations of an independent state (Court and Ghai, 1974). Higher education in Kenya can be traced back to 1922, when the then Makerere College in Uganda was established as a small technical college which was then expanded to meet the needs of the three East African countries, Kenya, Uganda, Tanganyika and Zanzibar, as well as Zambia 
and Malawi. From one university in 1970, the number has increased to six public universities, six University College and 17 private universities.

Over the last four decades, the social demands with respect to higher education in Kenya have clearly intensified. This has been exemplified by the rise in enrolment in public and private universities, the proliferation of more private universities and the establishment of the private wings (self sponsored programmes) in the public universities (Government of Kenya, 2005). Financing higher education in Kenya, like most African countries, was historically free, with the public purse covering both tuition and living allowances (Weldman, 1995). Higher education in Kenya is run by the Commission for Higher Education (CHE) established in 1995 under provisions of the University Act with some of the major functions such as; to accrediting universities; to promote the objectives of university. Although these functions are considerable statutory to $\mathrm{CHE}$ to run university education, a number of criticisms have been levelled at the operations of the organisation (Sifuna, 1998).

\section{Statement of the Problem}

A benchmarking exercise might rely exclusively on one particular approach or it might utilize a combination of approaches. The products of benchmarking range from improved networking, collaborative relationship, followed by benchmark information and a better understanding of practices, processes or performance and insights on how improvements might be made. Benchmarking practice models are defined in terms whether the benchmarking process is independent (no direct involvement of partners) or collaborative (active involvement of partners). According to Jackson (2000), benchmarking results in three different products: Improved networking, collaborative relationship and mutual understanding between participants; Benchmarking information in the form of text numerical or graphical information about the area of study for example evaluate the reports, guidelines, specifications, how to do it work books, specification and codes of best practices, exemplars of good conduct/different practice and statistics; A better understanding of practice, process or performance insights into how improvements might be made, this understanding can be retained among the participants, for example, in order to gain or maintain competitive advantage, or it can be disseminated more widely through conferences, workshops and publications.

This study attempted to examine the various benchmarking practices and processes (activities) used in higher education. The emergence of these purposes had been prompted by the need to draw a distinction between benchmarking for regulatory purposes and benchmarking for the development and improvement. Price (1994) defined benchmarking for continuous/development and competitive advantage as the open and collaborative evaluation of services and processes with the aim of emulating or improving the best available practice. Regulatory benchmarking is the process to facilitate the systematic comparison and evaluation of practice, process and performance to aid improvement and self-regulation.

Some of the yardsticks that the study used to assist in the identification of the processes and practices of higher education to be benchmarked, key among them were: the benchmarking activities classified according to the nature of the processes that underpin the activity; the four referencing processes as mechanism for comparison (Jackson and Lund, 2000a); benchmarking practice model- the four practice model (Jackson and Lund, 2000b); benchmarking for quality or standards (lund,1998;Town, 2000; price,2000); benchmarking assessment practice (QAA,1998c); credit and assessment regulations (Margham, 1998); benchmarking academic practice creation of directories or online database (Hounsell et al., 1996); departmental academic management (Burge et al,1996); the outcomes of learning (QAA subject benchmarking); benchmarking key skills (Hodgkinson,1996; 2000); quality assurance practice codes and the negotiable work-based learning (Coleman and Viggars 
2000). Hence, there was a challenge for higher education to develop benchmarking in a way that will help people learn a bout and improve their own practice while improving the overall capacity of the systems to develop, improve and regulate itself. Academic benchmarking is equated to subject benchmarking i.e. a bureaucratic process for the purpose of making them accountable for their standards. But the examples above show that benchmarking can support very different agenda.

Out of the seven public /state universities, the University of Nairobi offers most of the degree programmes and has been admitting $75 \%$ of the candidates who qualify for higher education. Only the University of Nairobi managed the $21^{\text {st }}$ position in Africa (UNESCO World Conference on Higher Education (Farquhar, 1998). Thus, regardless of the rapid expansion of university education, there are a number of challenges, which have made the Kenyan universities, rank lowly in the recent 2005 academic ranking of the world universities. According to the UNESCO World Conference on Higher Education, low funding from the exchequer, increased enrolment, limited access compared to the population level, increased enrolment without commensurate improvement in available resources and facilities, gender inequality and a low research capacity which does not support the development agenda, due to failure by the public

universities to attract and increase income from research grants and contracts which can be sourced for from government, local authorities, industry and commerce, failure to meet the industry and development needs, are among some of the problems facing universities in Kenya .The problems have led to fears that quality of education is in a downward trend in most of the public universities. This can be depicted in the number of the students seeking higher education outside the country and the brain drain due to poor staff remuneration.

In Kenya, a closer analysis of expenditure by the Ministry of Education showed that the education recurrent budget has risen from 33.41 percent of the total government recurrent budget in 2001/02 to 34 percent in 2004/05.The consequences have included lack of equipment, teaching material and other operation and maintenance expenditure outlays (Government of Kenya, 1993; 2005).

Given that the ability of governments to finance education and other social services is likely to continue to decline, the process needs to be revisited to ensure a more balanced and equitable educational system through benchmarking (Government of Kenya, 1993; 2005). Accordingly, more than a million Kenyan professionals live and work abroad, making the country one of the most heavily brain-drained in Africa. Damning statistics released by the Government showed that between 0.5 and 1.8 million Kenyans work overseas, although their skills were much needed locally. Additionally, although more than 30,000 Kenyans leave for higher studies overseas, less than 9,000 of them return home on completing their learning. Thus, when people who are highly skilled leave the country, or those who have acquired high skills do not return, it poses serious brain drain, robbing the country of essential human resource capacity to help in socioeconomic development. The possible strengths include the high quality Kenyan graduates employed and working elsewhere outside Kenya. The introduction of private wings, for example, the University of Nairobi Enterprises and Services (UNES) and the parallel programmes has given many Kenyan students at bachelors and postgraduate, an opportunity for higher education and saved the country 'forex'.

To this end, within a new global market, characterised by rapid information change, intense information flows and increasing competition through the reduction of barriers to trade and exchange, higher education institutions, particularly in Kenya, are slowly emerging as organisations driven by the commercial imperative of market led forces. Yet their strategies for resource utilisation are embedded in models of higher education institutions as public institutions rather than commercial organisations. This has been coupled with other major challenges such as: inadequate 
funding especially for research and development, quality and relevance, inadequate use of ICT, lack of a unified accreditation system, un-harmonised legal frameworks, inadequate management capacity, drug and substance abuse. Hence, there was a need to explore ways of reversing and addressing the above challenges through benchmarking the whole higher education sector, to meet the best practices for continuous improvement and regulatory purposes.

Kenyan public universities are not the only ones training students for undergraduate and postgraduate in Kenya and in the world; there are hundreds and they provide the learning opportunities in thousands of different programmes, courses and facilities. According to Spendolini, (1992), a university can use this fact to its advantage, by benchmarking against other universities and schools. What has not worked at another university may work pretty well in Kenya, under different circumstances. Major escalation of environmental turbulence and production to an unfamiliar world of marketing and above with new technology, competitors and enlightened customers, there is an unprecedented questioning of the firm's role in society (Ansoff and Mc Daniel, 1990).

From the foregoing, it was necessary to conduct a study documenting the benchmarking practices in the Kenyan public universities. Defining and documentation of a perfect benchmarking system was aimed at exploiting the opportunities in Kenya which included a very large base in higher education capacity, a number of institutions with infrastructural capacity and adequately trained human resource and the underutilised existing infrastructural and human resources capacity (Nyaigoti-Chacha, 2004).

A number of researches in benchmarking especially in higher education have been conducted in the past but none has been conducted locally. Jackson (2001) found out that benchmarking can support very different agenda driven by a need to learn in order to understand, improve and innovate; a collective commitment to self-determined improvement even in a competitive marketa new collegiality and models of working that are based on professional rather than public accountability. He suggested that the Learning and Teaching Support Network (LTSN) would help higher education communities make effective use of this benchmarking methodology; this was on a basis of UK higher education.

Although researches have been done on benchmarking locally, none has focused on higher education in Kenya. One particular local research by Amollo (2002) on benchmarking the order delivery process for continuous improvement in the Kenyan oil industry, suggested that there was a need for a study to be conducted to determine to what extent other companies outside the oil industry in Kenya use benchmarking as a continuous improvement tool. This study, therefore, is an attempt to document the benchmarking activities based only on the academic function of the Kenyan Public Universities.

The study was an attempt to answer the following questions:

- What were the Kenyan public universities doing to exploit all available opportunities for continuous improvement to meet worldclass status?

- What were some of the critical factors influencing the choice of the various benchmarking practices and activities in higher education while benchmarking?

- Which challenges were facing Kenyan public universities in benchmarking the academic function in higher education?

- What were the Kenyan public universities doing to benchmark themselves against best practices, processes and tools to reverse the challenges facing their quality of higher education?

\section{Research Strategy, Data Analysis, Findings and Discussions}

This section covers two subsections for first, research strategy followed by the data analysis, findings and discussions 


\section{Research Strategy}

This was a case study on the benchmarking practices in the Kenyan higher education, specifically public university education. The study was limited to public universities only and did not include other institutions of higher learning and private universities that offer higher education. A case study involves a careful and complete observation of a social unit, which is either, a person, institution, family, cultural group or an entire community-and emphasizes depth rather than the breadth of the study (Kothari, 1990). The case study research design was chosen other than for instance, the cross-sectional survey, because the objectives of the study required an in-depth understanding and information about the subject matter. The study was inquiring into public universities present and past benchmarking processes, practices and tools used if any to predict the future higher education situation based on continuous improvement, quality and competitiveness.

This study, therefore, constituted the seven public universities in Kenya as per the Commission of Higher Education report for December 2005. Bearing in mind the number, the study was conducted in form of a census. This was possible because the number was not too big; meaning the seven (7) public universities were visited within a very short duration of time. This entailed distribution of questionnaires to the informants in the academic function of all the pubic universities. The unit of analysis was the university's academic function and the 32 respondents sampled were the specialists in that function's operations. Rosco (1975) proposes a rule of the thumb for determining a sample size and says that a size of 30 to 500 is appropriate for most researches.

This study relied on primary data collection methods. The items in the instrument were developed from the literature review to assist in the collection of primary data. It was delivered to all the public universities to the various respondents i.e. heads of the academic function operations: Chairpersons, Deans of Faculties, principals and Registrars Academic Affairs of the various universities. The questionnaire was self administered in that it involved the 'drop-and-pick-later' approach. This gave the respondents ample amount of time to think through the questions before answering them. The questions were both closed and of open-ended type. The closed ended questionnaire aimed at obtaining of responses while the open-ended bit gave flexibility for the respondent to answer.

The process of data analysis involved several stages. Completed questionnaires were edited for completeness and consistency. The data was then coded and checked for any errors and omissions (Kaewsonth \& Harding, 1992). The data was analyzed using procedures within Statistical Package for Social Sciences (SPSS) _PC version 10 to get its feel. One basic form of analysis was performed i.e. simple descriptive uni-variate statistics for measured variables.

The responses from the open-ended questions were listed so to obtain proportions appropriately; the mean and standard deviation were used. The mean measured the average response of the population. The mode was used as an arithmetic measure of the most frequently identified observation. The standard deviation looked at the spread of the answers from the mean. For closed questions, a comparative analysis using distribution tables, quartiles (percentiles) and graphical analysis was done to ascertain whether there was a significant difference within the pattern of responses and to improve the presentation of the analyzed results for ease of interpretation.

\section{Data Analysis, Findings and Discussions}

The data is summarised and presented in the form of proportions, means, tables and graphs. Of the 53 informants who were sampled, 31 responded, thus a response rate of 58 percent.

Available Opportunities for Continuous Improvement to Meet World-Class Status

Graduates' Congruence to the Market and Degrees Marketability: The respondents 
were asked to rate their graduates congruence to market place and the marketability of the degree courses they offer. Of the 31 respondents, $35 \%$ of them rated the graduates' congruence with the market requirements and the marketability of degree programmes as excellent, $65 \%$ of them rated them as good an indication that the quality of the graduates is not yet at the top level of excellence. None indicated fair and bad. There is room towards excellence for Kenyan public universities. Carr (2000) demonstrated that, in the global market of higher education, there are clearly competitive advantages in establishing and maintaining a reputation for providing good quality education, high academic standards and world-class research output in the market place.

The Teaching and Learning Media Used Most by the University: The respondents were asked to give the most commonly used media in Teaching and Learning in the public universities and from the research results $23 \%$ of the respondents indicated that they used chalk and board, 13\% indicated the use of overhead projectors/ transparencies, $6 \%$ indicated the use of Computers and LCD Projectors, 58\% indicated the greatest use of Sliding and White or Felt-Boards. This is a strong indication that new media is replacing traditional media of teaching and learning.

Rating and Renewal Frequency of the (Continuous) Improvement Systems in the Universities: The respondents were asked to appraise the continuous improvement systems in place, where Benchmarking was a subset of it. Out of the 31 respondents who were sampled, $77 \%$ of them ranked their continuous improvement systems as good, $33 \%$ of them as fair and none as bad. This shows that public universities have some continuous improvement systems in place. This affirms Norman's (2001) proposition that; at its simplest competitive performance standard would consist merely of judging whether the achieved performance of an operation is better than, the same or worse than that of its competitors. For organisations to effectively and successfully benchmark for continuous improvement, there is need to scan the environment for new benchmarks. Respondents were required to indicate the frequency of renewal in their academic function and from the data, 56\% of the respondents in the survey renew their improvement practices annually while $45 \%$ are reviewed monthly. Semi-annually and continuously got no response. This is an indication that continuous improvement has a frame of renewal and not left to chance (Norman, 2001). Important trends detected, need to be monitored continuously, so as to detect changes, direction and rate the change. This will also assist in the review of the procedures from time to time.

\section{How the Universities' Academic Programmes compare to other Universities Globally: Every organisation} wants to know how it is fairing in the global market. The current market of higher education is tending towards a global village due to globalisation. The respondents were, therefore, to account how their programmes measure with the global market. From the research findings, $19 \%$ indicated that they have excellent programmes, while $81 \%$ indicated that they have good programmes, which indicates that there is a very big gap to make Kenyan public universities international centers of Excellence. According to Watson (1996), thus, for the public universities to compete in the global environment, they must have quality beyond the competition, technology before the competition and costs below the competition.

The External and Internal Drivers of Change in the University: Threats to any organisation come from outside and may influence greatly the scope and course of action. There is a need, therefore, to scan the external environment and establish what exactly dictates change (Jackson, 2000). Respondents were, therefore, asked to indicate the triggers that drive change from outside and inside the university in its academic function. From the research findings, customers/Students received 84\% while the Market place received $13 \%$ as Legislation received only $3 \%$. It was equally observed that majority of the universities used customers/students as major triggers of change externally. 
The need and frequency of renewal in any system for change for continuous improvement is always triggered by both internal and external factors. Respondents were, therefore, asked to indicate the triggers that drive change from within the university academic function. Actual Performance received $84 \%$ while the Monitoring systems or controls received $13 \%$ as Dysfunctional behavior received only $3 \%$. From the research data, majority of the universities used Actual Performance as major triggers of change internally. Lead benchmarking should extend beyond internal and eternal financial and nonfinancial measures focus lead performance measures. These are indeed the academic performance management literature documented as: "Predictive performance measures"; "Leading indicators"; "Proactiveleading indicators, preventive/subjective" (Kaplan and Norton, 2001).

\section{Benchmarking Practices}

Existence of Benchmarking Systems: The respondents were asked to indicate whether they do benchmark or not. From the research data, 58\% indicated that indeed they do. The higher education sector requires continuous improvement. There are many techniques that can be used to achieve continuous improvements, to give the customers: - students, sponsors, the employers, the community and the government high quality/zero-defect outputs. Benchmarking which is a continuous systematic measurement and comparisons aimed at seeking fresh approaches, implementing improvements and reviewing the benefits in higher education, is one of the techniques (Norman, 2001).

The Major Reason of Benchmarking: The respondents were asked to indicate their objective in benchmarking. The major objective of benchmarking is to achieve continuous improvements and from the research data, $68 \%$ indicated that it is for development and improvement, as 32\% indicated that they use it for Regulatory purposes. This affirms the major reason of any benchmarking exercise; APQC (1997) stressed that benchmarking methodology as a process of improving performance by continuously identifying, understanding and adapting outstanding practices and processes found inside and outside the organisation and implementing the results.

What Drives the Agenda Benchmarking: The respondents were asked to indicate what drives the agenda of learning, improvement, innovation and change towards a self-determined improvement. Higher education operations have ever emphasised professionalism as opposed to other issues like accountability and holistic systems. From the research findings, $80 \%$ of the respondents indicated that it was indeed the issue of professionalism, a major aspect of the academic function that drives their agenda of benchmarking. 13\% indicated overall capacity as $7 \%$ indicated public accountability, which is not an academic function. Thus, professionalism triggers adoption of benchmarking systems. This is in line with Jackson (2000) observations that the growth of benchmarking in higher education reflects a number of imperatives including: the search for a more effective way of regulating standards in a diverse, multipurpose mass system of higher education, the need to ensure that public resources are used as effectively as possible, provision of information to drive change in line with the government's social and economic agenda and to the public to inform choice and with market requirements. He further noted that benchmarking can and does serve a different agenda driven by a need to learn in order to understand, improve, change and innovate; a commitment to self-determined improvement; models of working that are based on professional rather than public accountability and processes that are founded on action research.

Areas to be benchmarked in Priority to Achieve World Class Status: The academic process of higher education has four key areas that make the process of training complete. The respondents were asked to indicate, in priory, the areas to be emulated, required creativity and innovation to achieve World Class Status and from the research data, under the quality of the outputs from the process, Result profiles 
were given priority (Rank $=1 ;>50 \%)$ ). Under the quality of inputs to the educational process, Quality of Staff was given priority (Rank $=1)$. Under the way in which quality is defined, Capacity to transform learners was also prioritised (Rank = 1). Lastly, for the quality of the process itself, Assessment, Recruitment and marketing and Research supervision were given priority $($ Rank $=1)$.

Indeed, the Quality of Staff, Result profiles and Assessment Capacity to transform learners, Recruitment and marketing and Research supervision are the major areas that make a sustainable university. This is true as evidenced globally in aspects ranging from benchmarking for quality or standards (Lund, 1998;Town, 2000; Price, 2000), benchmarking assessment practice (QAA, 1998c), credit and assessment regulations (Margham, 1998), benchmarking academic practice creation of directories or online database (Hounsell et al., 1996), departmental academic management (Burge et al, 1996), the outcomes of learning (QAA subject benchmarking), benchmarking key skills (Hodgkinson, 1996; 2000), quality assurance practice codes, and negotiable work-based learning (Coleman and Viggars 2000).

\section{The Most Common Learning Experience of} the University Students: In developing economies, online learning is the most common experience for the students to avoid bed based admissions and travelling expenses. The respondents were asked to indicate one of the most common learning experiences of the university students. This was to measure the potentiality of the Kenyan public universities to move from traditional learning experience to the modern e-learning. 53\% of the respondents indicated that the most common learning experience is campus based/school based, out of which, 13\% indicated boarders, while $29 \%$ indicated day scholars as $3 \%$ indicated distance learning and conducted in the work environment.

Expectations of Participation in
Benchmarking: There are many
expectations when organisations participate

in benchmarking processes and activities. The three below are the major expectations. The respondents were asked to indicate what they expect to achieve in participating in any benchmarking/systematic comparison exercise. From the research data, a significant proportion thinks that participating in benchmarking will give them a better understanding of practice, process or performance and insights of the academic operations and functions. This affirms Tapas' (1998) proposition that benchmarking is undoubtedly a very important tool for organisations to establish their goals, developing methods for achieving the goals and measuring performance.

Higher Education Quality Aspects to be Fully Benchmarked: On the areas of higher education (public universities) that need to be addressed fully through benchmarking; regarding practices, processes, procedures and activities to protect quality and standards of the education, table 4-8 shows the results that were obtained after ranking. Not all aspects of higher education can be fully addressed through benchmarking. Some are critical while others are not. The respondents were to rank the aspects of higher education on a scale of three level scales (critical, not critical and don't know). From the research data, the top six aspects considered critical (mean $\leq 2.0$ ) have to do with examinations and research. In any academic systems, Examinations in relation to external examiners, assessment boards, managing service teaching, rules for using credit, condonement of failure and arrangements for supervising research students constitute the key patents and reputation. Arrangement for reporting, substitution of failed modules, policies for assessing students and determination of academic standards ranked lowly since this being policy matters, they have good guidelines which supplement the academia function. This concurs with Carr's (2000) demonstration that, in the global market of higher education, there are clearly competitive advantages in establishing and maintaining a reputation for providing good quality education, high academic standards and world-class research output. 
Presence of International Academic practices: The Kenya system of education does not allow some practices that might make other international systems compatible in academia. The respondents were asked to indicate the presence of world recognised academic practices in place. From the research data, the universities pegging admissions to bed capacity with unilateral picking and assigning candidates to courses they are not suited for. But they don't allow students transfer their grades to other universities (outside) that offer similar courses; coupled with non-existence of online learning systems. This is owing to the fact that, benchmarking is one of the performance management strategies to setting realistic performance standards (Nahmia, 2000). It is also concerned with searching new ideas and practices, which must be able to be copied or adapted. The success of benchmarking, however, is largely due to more than its ability to set performance standards and enable organisations to copy one another. It is essentially about emulating, creativity and innovation (Cartin, 2000).

\section{Enrollment of Foreign Students and their}

Percentage: Most universities of the world have attracted students beyond their continents. This is a test of international reputation based on the quality and standards. From the data, $70 \%$ indicated that they don't attract students beyond the continent. This is probably why the Kenyan universities scored lowly in the recent 2005 ranking. The respondents were asked to quantify the enrolment/amount of foreign student. From the research data, there is an average of $3.30 \%$ foreign students' composition in the public universities, supposedly because the Kenyan public universities have a good number of challenges facing them (Sifuna, 1998).

\section{The Potential and Recommendations to Make Higher Education System a Net Exporter of Higher Education Services: The respondents were asked to indicate whether the Kenyan higher education has the potential of exporting its services and any other recommendations to make it}

achieve best practices in the area. From the research data, of the 30 respondents, 24 of them indicated that the higher education sector has a potential of being a net exporter of the services to outmaneuver South African competitors or even overtake tourism as a major foreign exchange earner. Six of them indicated that there is no such possibility. Kenya depends on tourism a lot as a major exporter to earn the government foreign exchange. The country has a potential to export its higher education services too. The recommendations that can transform the Kenyan higher education (especially public universities) sector a major exporter of academic service basically include; enhancement of government support and staff development, Building infrastructure and excellent research laboratories, Recruiting highly qualified staff with reasonable remuneration and developing cross border and joint curriculum and degree programmes.

\section{Use of the Different Types of Benchmarking}

There are various types of benchmarking. . The main types of benchmarking are; Strategic Benchmarking which involves examining the

long-term strategies and general approaches; Performance benchmarking or competitive benchmarking where institutions consider their position in relation to performance characteristics of key products and services; Process benchmarking which involves producing process maps to facilitate comparison; Functional/generic benchmarking where partners are drawn from different business sector; Internal benchmarking seeking partners within the same organisation; External Benchmarking/Best Practice Benchmarking which is done with outside organisations that are known to be best in class; International Benchmarking whereby good practice organisations are located in other countries. They can be implemented concurrently or one at a time. The respondents were asked to indicate the extent of use, whether they are in use or they are planning to make use of them. 
From the research data, the most common types of benchmarking in use are Development/Improvement, benchmarking, Internal benchmarking, Competitive/performance benchmarking, Process benchmarking and Collaborative benchmarking, this is highly related to the outcomes from the objectives and strategies of most public universities. Most public universities are also planning to make use of Functional/Generic benchmarking, International benchmarking and Independent benchmarking, this is the reason why they are not recognised internationally, their quality of education has been on the down ward trend and none has peculiar characteristics as they are all classified as public institutions. This is as per the different ways of classifying benchmarking processes as tackled in works of Spendolini (1992), Appleby (1999), Jackson and Lund (2000).

\section{Critical Factors Influencing the Choice of the Various Benchmarking Tools/Scope}

Benchmarking is a simple concept but quite complex in application, thus, not all benchmarking attempts succeed due to undisciplined planning approach and limited resources. The choice of benchmarking tools and scope depends on how excellent, good, bad or indifferent an organisation's operations are. Most critical factors influencing the choice of the various benchmarking tools and scope in an organisation acts as challenges to benchmarking (Camp, 1989). The respondents were asked to indicate three critical factors that have influenced the success of their benchmarking practices in their environs. From the research data, the three major challenge facing the benchmarking processes in Kenya are time and resource availability; limited duration, comparability and compatibility which is the probable reason why the institutions don't practice international benchmarking. Indeed, benchmarking is a simple concept but quite complex in application, thus, not all benchmarking attempts succeed due to undisciplined planning approach and limited resources.

\section{Summary and Conclusions}

In line with the two objectives of the study, the following summary and conclusions were arrived at with respect to the establishment and documentation of the benchmarking practices in the academic function of public universities in Kenya; and the identification of the challenges facing benchmarking of education in public universities in Kenyan higher education.

The study found out that the greater percentage of the staff in the academic function has a strong academic background majority of them with PhDs. The graduates' congruency to the market place was found to be good. The teaching and learning media commonly used was also found to be chalk and board. The rating and renewal of the (continuous) improvement systems in the universities was found to be good and annually, respectively. On how the universities' academic programmes compare to other universities globally, it was found that they are fairly good and not excellent. The internal and external drivers of change in the university were found to be students and actual performance respectively.

The study also found out that the public universities have benchmarking systems; the major reason of benchmarking was to achieve development and continuous improvement. Professional processes, not public accountability processes that are founded on action research, drove the agenda of benchmarking. The areas to be benchmarked in priority to achieve worldclass status were found to be result profiles, staff and capacity to transform learners, research supervision and assessment.

It was also found that the universities have very little potentiality to move from traditional learning experience to the modern e-learning since the most common learning experience of the university students is actually campus-based. It was also found that all the factors that influence the success of benchmarking process influence/affect the success of 
benchmarking in the public universities. It was also found that participating in benchmarking would give Kenyan public universities a better understanding of practice, process or performance and insights of the academic operations and functions. Higher education quality aspects to be fully benchmarked, regarding practices, processes, procedures and activities to protect quality and standards of the education were found to be structure of assessment boards, deployment of external examiners and formal mechanism to facilitate staff-student communication. The nature of programmes differing in numbers and capacities was the major reason why other public universities receive few students except the University of Nairobi.

Majority of the respondents also agreed with the 2005 academic ranking of the world universities, recent spotlight evaluation of the world-renowned universities. The Kenyan public universities ranked lowly due to lack of ICT connectivity, limited resources and brain drain coupled with diminishing government funding. The most underutilised opportunity in the Kenyan public universities is a very large base in higher education capacity. The challenge of international academic practices with respect to admissions is that the Kenya system of education does not allow some practices that might make other international systems compatible in academia for example the universities peg admissions to bed capacity with unilateral picking and assigning candidates to courses they are not suited for.

It was also established that, the average number of foreign student population is $3 \%$ in the Kenyan public universities; a probable reason why the Kenyan universities scored lowly in the recent ranking. The higher education sector has a potential of being a net exporter of the services to outmaneuver south African competitors or even overtake tourism as a major foreign exchange earner and the major steps to be undertaken so as to achieve this goal basically include; enhancement of government support and staff development, building infrastructure and excellent research laboratories, recruiting highly qualified staff with reasonable remuneration and developing cross border and joint curriculum and degree programmes. The major step being undertaken by Kenyan public universities to achieve world-class status is benchmarking and strict adhering to their strategic plans. Improvement in the quality, standards of education and library services management were key areas that seemed to demand continuous comparisons. This is probable since the two go hand in hand in the academia function. Estates and energy management scored lowly. The public universities are perceived in terms of the quality of education in higher education other than reputation and profit. Comparing processes with those of competitors in higher education seemed to be the main way of making comparisons, probably because of the similar nature of processes, as opposed to those outside the academic function.

Collaborative group partnership, brokered models involving an individual or agency intervening and collaborative one- to - one partnership are the most common models used in the benchmarking towards improvement in the quality and standards of the Kenyan higher education. Data centers and direct contact are the major sources of information on benchmarking processes. Action research and performance indicators have the highest attention as the sources of information on benchmarks. The most common types of benchmarking in use are development/improvement benchmarking, internal benchmarking, competitive/performance benchmarking, Process benchmarking and collaborative benchmarking; this is highly related to the outcomes from the objectives and strategies of most public universities. Most public universities are also planning to make use of functional/generic benchmarking, international benchmarking and independent benchmarking, this is the reason why they are not recognised internationally, their quality of education has been on the down ward trend and none has peculiar characteristics as they are all classified as public institutions. 
The three most critical factors facing the benchmarking processes in Kenya are time and resource availability; limited duration, Comparability and compatibility which is the probable reason why the institutions don't practice international benchmarking.

From the research findings, it was worthy modeling the benchmarking practice in higher education as follows before making conclusion:

Therefore, in the benchmarking practice in higher education, the first step is to establish higher education concerns in benchmarking, which is then followed by the identification of key areas to be benchmarked. The two will the enable an institution to determine the objective of benchmarking. The identification of sources of information will be followed by the implementation of the best benchmarks to address the concerns. Any challenges identified should be addressed in order to achieve the best practices.

Based on the results from data analysis and findings of the research, one can safely conclude the following; First, Continuous improvement systems should be renewed annually. The external drivers of change/continuous improvements in public universities are the customers/students as opposed to legislation, while the major internal trigger of change is the actual performance. The public universities effectively and successfully benchmark for continuous improvement. Most academic programmes have not reached excellent levels in the global market scale since there is a very big gap to make Kenyan public universities international Centers of Excellence. This concurs with Sarkis' (2001) observations that benchmarking is a continuous, systematic process for evaluating the products, services and work process of organisations that are recognised as representing best practices, for the purpose of organisational improvement.

Secondly, the study also found out that, those who benchmark, their agenda emphasizes professionalism as opposed to other issues like accountability and holistic systems. Thus, professionalism triggers adoption of benchmarking systems. The areas that need to be given first priority in benchmarking the higher education were found to be; the quality of the outputs from the process where result profiles should be given priority; the quality of inputs to the educational process where quality of staff should be given priority; the way in which quality is defined where capacity to transform learners should be prioritised. Lastly, under the quality of the process itself, assessment, recruitment, marketing and research supervision should be given priority. These are the major areas that make a sustainable university. Increasingly, benchmarking is occurring at the input, process stage, which is otherwise known as upstream elements of the organisation whereby lead benchmarks of performance are readily identified. Therefore, this is clearly evident that benchmarking must evolve from being backward looking to forward looking (Sarkis, 2001).

Thirdly, all the five major factors that influence the success or failure of any benchmarking systems and process hold while benchmarking the higher education. The public universities' objectives of participating in benchmarking processes and activities are aimed at a better understanding of practice, process or performance and insights of the academic operations and functions. The steps being undertaken to achieve world-class status especially, after the recent low score in the 2005 world ranking of public universities is only through benchmarking and strict adhering to their strategic plans.

Fourthly, the public universities' visions and missions are perceived as the strongest competitors in higher education as opposed to the most admired in higher education. They only tailor their benchmarks through a comparing process with those of competitors in higher opposed to other best practices outside the academic function. Out of the various models that can be used when benchmarking with the competitors, collaborative group partnership, brokered models involving an individual or agency intervening and collaborative one- to - one partnership are the most common models used by Kenyan Public universities in the 
benchmarking towards improvement in the quality and standards of education. This was possible since no universities can survive in a vacuum and hold substantial expertise to go it alone using independent self-referencing models. This is in line with the literature on benchmarking typologies, which looked at benchmarking as a structured process, a step-by-step process model, which provides a common language within organisations (Spendolini, 1992).

Fifthly, the public universities source information about other organisations' processes from: data centers, libraries and through direct contact. Benchmarking, as a method of self-evaluation is based on searching for and creating reference points or benchmarks and understanding the reasons why they are reference points. There is little usage of Internet due to lack of a good infrastructure for ICT. Benchmarking activities can be classified according to the referencing processes as a mechanism for comparison that is used. The Kenyan public universities use action research and performance indicators as the sources of referencing information on benchmarks.
Sixthly, in spite of the various types of benchmarking which can be implemented concurrently or one at a time, the study found out that the most common types of benchmarking in use are development/ improvement benchmarking, internal benchmarking, competitive/ performance benchmarking, Process benchmarking and collaborative benchmarking, this is highly related to the outcomes from the objectives and strategies of most public universities. Most public universities are also planning to make use of functional/generic benchmarking, international benchmarking and independent benchmarking, this is why most public universities are not recognised internationally, their quality of education has been on the downward trend and none has peculiar characteristics as they are all classified as public institutions.

Finally, the three critical factors that have influenced the success of public universities' benchmarking practices in their environs are:

- time and resource availability

- limited duration,

- comparability and compatibility. 
Figure 3-1: The Benchmarking Practice in Higher Education

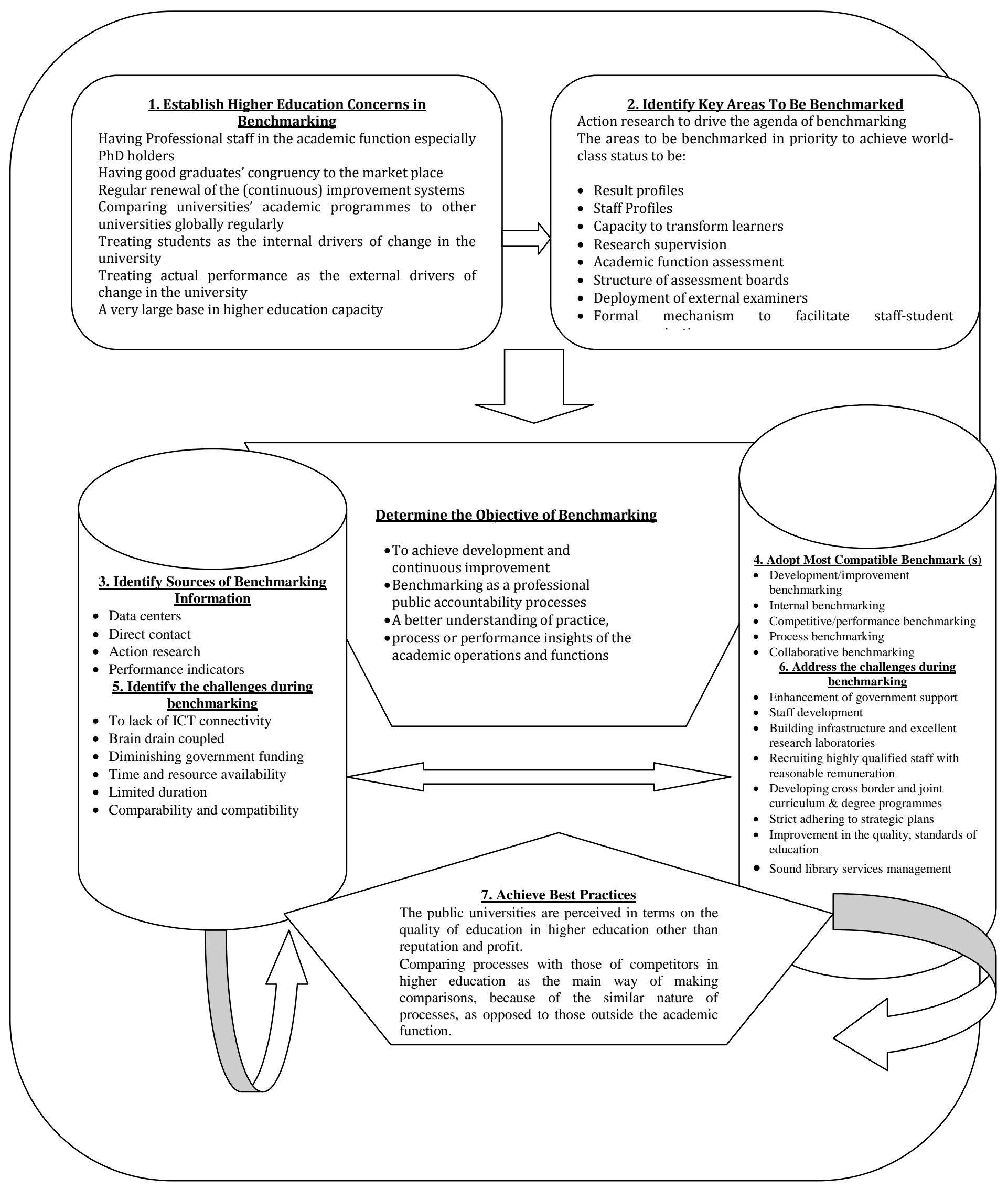




\section{Recommendations}

\section{Recommendations for Improvement}

The following aspects of academia should be fully addressed through benchmarking to protect quality and standards of the education:

With respect to examinations and research, there should be clear academic systems regarding external examiners, assessment boards, managing service teaching, rules for using credit, condonement of failure and arrangements for supervising research students which constitute the key patents in higher education and reputation.

The government, being the key player in the Kenyan higher education sector, should carry out the following responsibilities: Champion the ICT connectivity in all public and private universities. This is because ICT connections in Kenya are very expensive and slow in speed, since they are via satellite, which is a limitation due to the absence of optic-fiber cable connectivity to the other part of the world; Increase the volume of resources and financing form the exchequer the public universities' expenditure kit. The government should increase its research grants and mobilize the local authorities, NGOs, Household, communities and private sectors to assist in the financing and development of academic programmes.

The following key areas of management that affect the academia function directly and indirectly should be improved through benchmarking to improve the academia function of the universities: Improve the quality and standards of education through sound library services management through continuous comparisons since the two go hand in hand in the academia function. Estates and energy management should follow this.

\section{Limitations}

Given the geographical disperse of the universities and their schools/campuses; very limited time coupled with insufficient funds to meet commuting expenses for the research, this was a major constraint. Use of descriptive statistics: The use of descriptive statistics tended to combine characteristics together hence, individual characteristics of the public universities do out come out. It generalised the responses of the different categories of informants who may not share the same experience in the academia function. Most of the informants were reluctant to participate in the research and had to be really convinced that it was only an academic exercise.

\section{Suggestion for Further Research}

Benchmarking as a continuous improvement tool is applicable in all industries. The researcher recommends a study to be conducted to determine the extent other companies outside the higher education sector use benchmarking as a continuous tool. Such studies will help in highlighting challenges facing Kenyan organisations in the implementation of benchmarking. This might shade some light as to why Kenyan organisations have not been able to reach world-class status in their operations. Policy markers would then be able to initiate appropriate reforms based on these challenges.

\section{References}

Abagi, 0. (1997). 'Public and Private Investment in Primary Education in Kenya: An Agenda for Action,' Institute of Policy Analysis and Research Discussion Paper No 005/97. Nairobi: Institute of Policy Analysis and Research.

Amolo, T. 0. (2002). 'Benchmarking the Order Delivery Process in the Oil Industry,' University of Nairobi. Unpublished MBA thesis.

Ansoff, H. I. \& Mc Daniel, J. (1990). Implanting Strategic Management: Prentice Hall 2nd Edition.

Appleby, A. (1995). "Benchmarking Theory: a Framework for the Business World as a Context for its Application in Higher Education," Smith, H., Armstrong, M. and Brown, S. (Eds). Benchmarking and Threshold Standards, Kogan page, London. 
APQC (1993). 'American Productivity and Quality Center: Basics of Benchmarking,' Houston, Texas.

Bridges, P. et al. (1999). "Discipline Related Marking Behavior Using Percentages: A Potential Cause of Inequity in Assessment," Assessment and Evaluation in Higher Education, Volume 24, No. 3

Burge, S. E., Jackson, N. \& Tannock, J. D. T. (1996). "Specification for Quality Management Framework at Departmental Level," Occasional paper number 9, Engineering Professors' Council, Warwick University.

Camp, R. C. (1998). 'Benchmarking: The Search for Industry Best Practices that Lead to Superior Performance,' ASQC Quality Press, Milwaukee WI.

Cartin, T. J. (2000). Principles and Practices of Organizational Performance Excellence.

Cave, M., Hanney, S., Henkel, M. \& Kogan, M. (1997). The Use of Performance Indicators in Higher Education: The Challenge of the Quality Movement, Jessica Kingsley publishers.

Chacha Nyaigoti Chacha (2004). 'Performing Higher Education in Kenya: Naivasha,' Kenya. State University of New York workshop with the parliamentary committee on Education, science and technology.

Coleman, R. \& Viggars, L. (2000). "Benchmarking Student Recruitment: The UCAS Institutional Planning Service," Jackson, N. and Lund, H. (Eds) Benchmarking for Higher Education, open University press, Buckingham.

Court, D. \& Ghai, D (Eds) (1974). Education, Society and Development: New Perspectives From Kenya. Nairobi, Oxford University press.

Dewhurst F.et al. (2001). Total Quality Management in Public Organizations, an Examination of the Issues; Managing Service Quality volume 9 number 4 pp 265-273.
Fairclough, N. (2001). Critical Discourse Analysis as a Method in Social Scientific Research. Wodak, Ruth \& Meyer, Michael (Eds.). Methods of Critical Discourse Analysis, London: Sage.

Farquhar, R. H. (1998). "Higher Education Benchmarking in Canada and the United States of America", Schofield, A. (Ed.) Benchmarking in Higher Education: An International Review, CHEMS, London and UNESCO, Paris.

Fielden, J. \& Carr, M. (2000). "CHEMS International Benchmarking Club", Jackson N. and Lund, H. (Eds). Benchmarking for Higher Education, Open University Press, Buckingham.

Garvin, B. A. (1993). 'Building a Learning Organization,' Harvard Business Review, volume 71 number 4 pp 78-91.

Government of Kenya, (1993). Development Plan 1994 -1996. Nairobi: Government Printers.

Government of Kenya, (1996). Economic Survey. Nairobi: Government Printers.

Government of Kenya, (2005). Economic Survey. Nairobi: Government Printers.

HEQC (1996). Inter-Institutional Variability of Degree Results: An Analysis in Selected Subjects, HEQC, London.

Higher Education Statistics Agency, (HESA) (1997). Students in Higher Education Institutions 1996/97, HESA, Cheltenham.

Hodgkinson, L. (1996). "Changing the Higher Education Curriculum: Towards a Systematic Approach to Skills Development for Education and Employment," Buckingham.

Hodgkinson, L. (2000). "Benchmarking Key Skills Using National Standards: The Open University Experience," Jackson, N. and Lund, H. (Eds). Benchmarking for Higher Education, 
Hounsell, D., McCulloch, M. \& Scott, M. (1996). The ASSHE Inventory: Changing Assessment Practices in Scottish Higher Education, Center for Teaching, Learning and Assessment. University of Edinburgh.

Jackson, N. J. (2000). "An Approach to Quantitative Benchmarking," Jackson, N. and Lund, H. (Eds). Benchmarking for Higher education, Open University Press, Buckingham.

Jackson, N. J. (2001). "Implication of Benchmarking for Curriculum Design and the Assessment of Students Learning," LTSN Generic Center Working Paper.

Jackson, N. J. (2001) "Benchmarking in U.K Higher Education, an Overview," Quality Assurance in Education volume 9 number 4 pp218-235, MCB university Press.

Jackson, N. J. \& Lund, H. (2000a). "Introduction to Benchmarking," Jackson, N. and Lund, H. (Eds). Benchmarking for Higher Education, Open University Press, Buckingham.

Jackson, N. J. \& Lund, H. (2000b). "Benchmarking for Higher Education: Taking Stock," Jackson, N. and Lund, H. (Eds). Benchmarking for Higher Education, Open University Press, Buckingham.

Johnes, J. \& Taylor, J. (1990). Performance Indicators in Higher Education, SRHE and Open University Press, Buckingham.

Kaewsonth \& Harding, (1992). Eds, Management in Developing Countries, Routledge, London

Kaplan, R. S. \& Norton, D. P. (2001). The Strategy-Focused Organization: How Balanced Scorecard Companies Thrive in the New Business Environment. Boston, MA: Harvard Business School Press.

Kells, H. R. (1992). "Self-Regulation in Higher Education: A Multi-National Perspective on Collaboration Systems of Quality Assurance and Control," Higher Education Policy series No. 15, Jessica Kingsley Publishers, London and Philadelphia, PA.
Kells, H. R. (1995). Self-study Processes: A Guide to Self-evaluation in Higher Education, Orynx Press, Phoenix, AZ.

Kothari, C. R. (1990). Research Methodology: Methods and Techniques, Wishira Prakashan, 2nd edition.

Laeven, H. \& Smit, A. (2003). A Project to Benchmark University Libraries in the Netherlands volume 24 numbers 6/7 pp 291-304 @ MCB UP limited.

Leibfried, K. H. J. \& McNair, C. J. (1992). Benchmarking: A Tool for Continuous Improvement, Harper Collins.

Lund (2000). "HEFCE's Value for Money Studies," Jackson, N. and Lund, H. (Eds.) Benchmarking for Higher Education, Open University Press Buckingham.

Lund, H. (1998). "Benchmarking in UK Higher Education," Shofield A. (Ed.). Benchmarking in Higher Education: An International Review, CHEMS, London and UNESCO, Paris. Pp. 47-64.

Mackie, D. (2000). "Universities 21," Jackson, N. and Lund, H. (Eds). Benchmarking for Higher Education, Open University Press, Buckigham.

Margham, P. (1998). "Benchmarking of Regulatory Framework in Northern Universities", Jackson, N. (Ed.). Pilot Studies in Benchmarking Assessment Practice, QAA, Glouester.

Morgan, R. (2000). "Benchmarking The Learning Environment," Jackson, N. and Lund, H. (Eds). Benchmarking for Higher Education, Open University Press, Buckingham.

Nahmias, S. (2000). "Production and Operations Analysis," Fourth Edition pp 691.

NUCCAT (1998). "Modularity and Credit Framework," the NUCCAT survey and 1998 Conference Report, Northern Universities Consortium for Credit Accumulation and Transfer, February. 
Oketch, M. (2009). "Private-public Mix in the Provision of Higher Education in East Africa: Stakeholders Perceptions. Compare," A Journal of Comparative and International Education, Vol.39, Issue 1, pp. 21-33',

Price, I. (1994). "A Plan Guide to Benchmarking," Special Report of the Unit for Facilities Management Research, Sheffield Hallam University, Sheffield.

QAA (1998a). "An agenda for Quality," Consultation Issue of Higher Quality, The Bulletin of the Quality Assurance Agency For Higher Education, Gloucester, March.

QAA (1998c). Pilot Studies in Benchmarking; Assessment Practice in UK higher Education, Quality Assurance Agency for Higher Education, Gloucester.

Rosco, S. U. (1975). "Research Methods for Business, a Skill Building Approach," 2nd ed. Wiley \&Sons, New York

Sifuna, D. N. (1998). "The Government of Kenyan Public Universities in Research in Post-Secondary Education," Volume 3, number 2 .

Spendolini, M. J. (1992). The Benchmarking Book, AMACOM, New York, NY.
Student Physician, (1957). New Oxford English Dictionary 6th Edition

Town, S. (2000). Benchmarking the Learning Infrastructure; Library and Information Services Case Study", Jackson, N. and Lund, H. (Eds). Benchmarking for Higher Education, Open University Press, Buckigham.

UNESCO (1998). World Conference on Higher Education. UNESCO, Paris.

Watson, D. (1996). "Quality Assessment and Self Regulation, the English experience, 1992-94", Higher Education quarterly, volume 49 number 4, pp 326-40.

Weldman, J. (1995). Diversifying Finance of Higher Education Systems in the Third World; the Case of Kenya

World Bank, (1995a). Technological Capabilities and Learning in African Enterprises. Washington, DC: The World Bank

Wragg, C. (1998). "Commonwealth University Management Benchmarking Club," in Schofield, A. (Ed.). Benchmarking in Higher Education: An International Review, CHEMS, London and UNESCO, Paris, pp. $79-90$ 